\title{
El aumento de las noticias falseadas y sus consecuencias en el que hacer de los profesionales de la información en televisión
}

\author{
The increase of the falsified news and its consequences in the \\ work of the professionals of the information
}

\author{
Nuria Sánchez-Gey Valenzuela, Universidad de Sevilla, España \\ Calle San Fernando, 4, 41004 \\ email_nuriacris@yahoo.es | Orcid: https://orcid.org/0000-0002-4891-9134
}

DOI: http://dx.doi.org/10.12795/Ambitos.2019.i45.10

\begin{abstract}
Resumen
En este artículo analizamos el aumento de noticias falseadas o fake news en medio televisivo. Consideramos justificado este estudio ya que éstas pueden no sólo influir en el trabajo de los periodistas, sino que podrían afectar a las informaciones que llegan a los espectadores y a su concepción del mundo. El objetivo central es saber si esto está sucediendo y sus causas.

Para ello utilizamos el enfoque estructural, que cómo define Ramón Reig (2017) se refiere a un enfoque que relaciona unos elementos con otros para comprender el mundo, teniendo en cuenta el contexto y la perspectiva. Asimismo, hemos utilizado el empirismo profesional.
\end{abstract}


Los resultados indican que un $20 \%$ asegura haber dado alguna información falseada. Concluimos que los profesionales consideran que poseen herramientas contra las noticias falseadas pero que la velocidad, e incluso la audiencia, hacen que lleguen a los medios y a los telespectadores.

\begin{abstract}
In this article we want to analyze the increase of falsified news [i] or fake news in television media. We consider this study justified since they can not only influence the work of journalists, but could also affect the information that reaches viewers and their conception of the world. The central objective is to know if this is happening and its causes.

For this we use the structural approach, which as defined Ramón Reig (2017) refers to an approach that relates some elements with others to understand the world, taking into account the context and perspective. We have also used professional empiricism.

The results indicate that $20 \%$ say they have given some false information. We conclude that the professionals consider that they have tools against the falsified news but that the speed and even the audience make them reach the media and the viewers.
\end{abstract}

Palabras clave: Fake News. Periodista. Redes Sociales. Medios de comunicación. Derecho a la información

Keywords: Fake News. Journalists. Social Networks. Mass Media. Right to information.

\title{
1. INTRODUCCIÓN
}

El aumento de las Redes Sociales (RRSS) y las Nuevas Tecnologías de la Información han hecho que el incremento de datos fluya en la sociedad, pero a su vez se plantea la duda de si a más información, más datos, quiere decir mejor información o, todo lo contrario. El poco control a la hora de que dichos datos sean publicados y pasen a ser de dominio público, debido a las pocas barreras y a la inmediatez, hace que cada día tanto el público en general como el profesional de la información en particular se encuentren con infinidad de datos que les llegan sin filtro y que ellos deben saber valorar. Pero no sólo eso, sino que la mayoría de las informaciones no son dadas por profesionales de la información y a esto se une algo aún más grave y es el hecho de que entre las informaciones falsas que se transmiten hay muchas que se hacen públicas intencionadamente. Son las que se han calificado con el nombre noticias falseadas, y que corren por la Red y llegan incluso hasta los medios de comunicación. En esta situación, ¿cuál es el papel de los profesionales de la comunicación como altavoces de los hechos noticiosos? ¿Cuál es la responsabilidad de un periodista? ¿Dónde queda la función social de los medios que recoge la Constitución Española de trasmitir informaciones veraces? En la situación actual consideramos fundamental abordar este estudio. 
Este artículo parte de los objetivos generales y específicos de esta investigación. Asimismo, se expondrán las hipótesis de la investigación. Posteriormente se detallará la metodología y métodos utilizados. En el estado de la cuestión se hará un repaso de los estudios anteriores sobre el tema investigado para definir de dónde surge dicho estudio. A lo largo del desarrollo del artículo veremos herramientas para distinguir las noticias falseadas, instrumentos para combatirlas y expondremos casos concretos de este tipo de noticias. Tras el cuerpo central del artículo daremos los resultados de la investigación, resaltando los datos más relevantes. Por último, incluiremos las discusiones y conclusiones extraídas donde presentaremos los descubrimientos a los que hemos llegado y posibles líneas para investigaciones futuras.

El objetivo central de este trabajo de investigación es poder hacer una aproximación, mediante el análisis, de las noticias falseadas que actualmente llegan a los medios de comunicación. Con ello pretendemos ayudar a distinguir y combatir las que actualmente llegan a los periodistas que trabajan en los medios de comunicación. Para ellos pretendemos también señalar herramientas que ayuden a determinar cuándo una noticia es falseada. Con estos datos podremos establecer parámetros para saber qué hacer para evitar que los profesionales de la comunicación sean utilizados inconscientemente como altavoces de estas noticas interesadas. Asimismo, perseguimos proteger al público en general, a la sociedad, de dichas noticias interesadas, ya que uno de los derechos fundamentales que la Constitución Española reconoce y protege el derecho a recibir libremente información veraz por cualquier medio de comunicación, es decir, el derecho a ser informado de manera veraz por los medios de comunicación.

Partimos de la hipótesis de que se ha producido un aumento de las noticias falseadas que llegan a los medios de comunicación y que esto afecta a la labor diaria de los profesionales que trabajan en el medio televisivo y también a las informaciones que llegan a los telespectadores, por tanto, a su concepción del mundo.

Dentro de las hipótesis secundarias señalar que el aumento de las noticias falseadas afecta a la función social del periodista y a su vez al derecho fundamental de los ciudadanos recogido en la Constitución Española de recibir información "veraz" a través de los medios de comunicación.

Otra de las hipótesis es si el aumento del uso de las Redes Sociales por parte de los profesionales de la información ha afectado de forma positiva o negativa a la hora de realizar su labor y si el hecho de usar las Redes Sociales como herramienta de trabajo ha podido afectar de forma negativa. Ya otros investigadores han situado los inicios de las noticias falseadas y de la posverdad en este fenómeno. Así Carrera expresa:

En suma, la noción de posverdad y sus aledaños -fake news, etc.-, que ha florecido a la sombra del gran árbol de Internet y de la supuesta cacofonía y 
superabundancia informativas que se le atribuyen, presupone y postula la de transparencia discursiva y la existencia de relatos simple y llanamente verdaderos. Como he escrito en otro lugar: 'El concepto mismo de transparencia implica una supuesta negación del relato como estructura retórica intencional, destinada a la creación de efectos y basada en un sistema de desigualdades y restricciones enunciativas, en nombre de lo que podríamos denominar un supuesto striptease sistémico que operaría más allá de las determinaciones y condicionamientos culturales, en un entorno global y transcultural (o multicultural). Frente a la noción clásica de espectáculo (que denota artificiosidad y se concibe como claramente cultural y discursiva), se enuncia una especie de vuelta a la naturaleza y a la espontaneidad de los orígenes, algo que, cuando se aplica al contexto de los mass media, espacio retórico y artificial por antonomasia, no puede entenderse sino como mera metáfora de un orden del relato cada vez más cerrado, restrictivo y dogmático bajo la apariencia de la infinita variedad y una irrestricta libertad de elección'.( 2017, p.45)

También incluimos como hipótesis que la creación y difusión de estas noticias falseadas no es algo espontáneo ni inocente, sino que detrás de esta intención hay un interés concreto.

Metodológicamente consideramos que en el siglo XXI es imposible hacer un trabajo de investigación sobre medios de comunicación sin que se haga un análisis estructural. Es decir, no se pueden analizar los medios de comunicación por sí mismos. Sólo se podrán analizar si se llega más allá. Si se incluye en el análisis qué hay detrás de éstos, que hay detrás de lo aparente. Muy lejos han quedado ya los periódicos cuyos dueños eran periodistas y ellos mismos escribían las noticias que ellos decidian y se llevan los beneficios. Ahora los medios de comunicación son grandes empresas y los periodistas son simples asalariados. Así lo adelantaba Ramón Reig (2003). Este enfoque estructural académicamente se define como Economía Política de la Comunicación, la Información y la Cultura.

Junto a la técnica concreta, para la realización del análisis hay que tener en cuenta que además de investigadores somos periodistas. Trabajamos desde hace más de 15 años dentro de esta estructura mediática que pretendemos analizar, y lo que hemos vivido y vivimos profesionalmente impregnará nuestra manera de hacer este estudio y los resultados que de éste extraiga. Algo que el catedrático Ramón Reig (2011) ha llegado a llamar "empirismo profesional" basándose en el término acuñado por periodistas latinoamericanos. Un término que es inevitable desligar de este trabajo de investigación.

Pero para entender qué es el empirismo profesional primero vamos a definir qué es el empirismo. Según la Real Academia de la Lengua Española (RAE), empirismo es el conocimiento que se origina desde la experiencia. $Y$ a su vez, el sistema filosófico 
basado fundamentalmente en los datos de la experiencia. Es decir que el empirismo epistemológico es la ciencia a la que se llega a través de la experiencia, y si unimos el adjetivo profesional, pues tendremos la ciencia, el conocimiento, al que se llega tras la experiencia profesional, en este caso, tras la vivencia de la profesión periodística. Además, hay que tener en cuenta que en la profesión periodística se experimenta a través de la observación, incluida en ésta tanto la observación directa, como en la observación directa participante.

Por todo esto, vamos a llevar a cabo un análisis no solo cuantitativo sino cualitativo a través de los testimonios recogidos entre profesionales de la comunicación sino una análisis estructural y empírico.

Para poder analizar el momento actual en el que nos encontramos hemos acudido a profesionales que realizan su labor en los medios televisivos más representativos en Sevilla. Así hemos podido contar con el testimonio de profesionales que actualmente trabajan en el grupo Mediaset (Telecinco y Cuatro), en Atresmedia (Antena 3 TV y La Sexta), $13 T V$ y Europapress. Para seleccionar a los componentes de esta muestra se ha exigido que los participantes ejercieran como periodistas en la actualidad, llevaran trabajando en los medios de comunicación un mínimo de 5 años y fueran licenciados en Comunicación. En el método se ha recurrido tanto al análisis cuantitativo como cualitativo, y la aportación de las fuentes ha sido a través del cuestionario de respuestas abiertas. Asimismo, se ha utilizado la observación participante dado que la investigadora que lleva a cabo este trabajo ha ejercido durante más de una década en el medio televisivo.

En relación al fenómeno de estas noticias falseadas, principalmente sobre su explosión y proliferación, al ser un hecho muy reciente, no existen hay muchos estudios previos. Pero en los últimos años son muchos los investigadores que han analizado parcelas concretas del fenómeno. No obstante, aunque el excesivo aumento de las noticias falseadas sea un caso nuevo, su existencia no.

Ralph Keyes ya escribió en 2004 el libro Dishonesty and Deception in Contemparary Life, como relata Luis Meyer en la revista Ethic de febrero de este año (No lo llames posverdad, llámalo posperiodismo). Su colega Eric Alterman lo definió definitivamente como "arma política de desinformación". El mismo autor cita a Noam Chomsky que, eludiendo la palabra posverdad, elaboró una célebre lista: '10 Estrategias de Manipulación' entre las que incluye las técnicas para ablandar emotivamente los mensajes con la finalidad de cortocircuitar el sentido crítico y analítico de los ciudadanos.

Es cierto que la existencia de estas falsas noticias no es nueva, pero sí el aumento en el día a día del periodismo. La irrupción de las redes sociales y sobre todo su democratización y las nuevas tecnologías de comunicación e información han hecho que proliferaran las noticias falsas. No obstante, la entrada a las redacciones 
periodísticas puede verse marcada por la llegada de Donald Trump al poder. Ha sido un hito para el periodismo que un presidente la primera potencia mundial haya caracterizado la campaña para llegar a presidente y posterior mandato en la difusión de noticias falseadas. La génesis de esta palabra también puede verse refrendada con que fue escogida como palabra del año del Diccionario Oxford.

Entre los 4.500 millones de palabras que consideraron los editores de los Diccionarios de Oxford, en los últimos 12 meses, las palabras que más aumentaron en uso (un 365\%) este año fueron la combinación "fake news" (noticias falsas). Por esta razón, la fórmula ha sido elegida como la palabra del año 2017. El año pasado la escogida fue "post-truth" (pos-verdad), que el mismo diccionario viene a definir como "actitud de resistencia emocional ante hechos y pruebas objetivas". O creerse lo que uno quiere al margen de lo demostrado con hechos. Ambas palabras apuntan a que la política internacional determina los vaivenes del vocabulario dominante, primero en inglés o mantenido como anglicismo y después traducido a otras lenguas. (2017)

Un término con carácter político pero que posteriormente ha ido alcanzando a otros ámbitos de la vida.

Así el periodista el periodista Esteban Illades (2018) asegura que jamás ha sido tan fácil ser engañado: a la censura y el espionaje se han sumado la sobreinformación y las fake news. En este escenario, que parece sacado de una distopía orwelliana, la ética periodística, la confirmación y el rigor parecen reliquias olvidadas.

En este caso hay dos problemas que marcar. Las noticias falseadas con intereses concretos o las que llegan al profesional de la información y al espectador por falta de buena diligencia profesional por parte de éste.

La generación de contenidos erróneos no siempre se trataría de una estrategia calculada, ya que incluso profesionales de la información deben contar con las competencias que les permitan identificar fuentes digitales válidas como referentes para sus trabajos, estar en capacidad de filtrar los miles de recursos disponibles sobre su tema en la Red, muchos de los cuales pueden ser engañosos y poco fiables. Cuando muchos se limitan a buscar referentes en los motores de búsqueda, no siempre se encuentra información válida y relevante. Esto puede contribuir en el oscurantismo, la ignorancia y la desinformación. (Lotero-Echeverri, G.; Romero-Rodríguez, L. M.; Pérez-Rodríguez, M. A., 2018, p.298)

Otro periodista que ha querido profundizar en el fenómeno que nos ocupa es Marc Amorós. En su obra Amorós nos recuerda que las redes sociales permiten transmitir las noticias falsas a una velocidad vertiginosa y transforman en periodista a cualquiera que tenga una cuenta en Twitter o Facebook. Asimismo, pone un ejemplo muy concreto que 
puede señalar la facilidad y la importancia de hacer algo ante el aumento de estas noticias falseadas. Incluye el testimonio de un chico macedonio que publicó una noticia falseada durante la campaña que en 2016 enfrentó a Donald Trump con Hillary Clinton:

Luego de copiar y pegar varios artículos, los adorné con un título sugerente y llamativo, pagué una campaña en Facebook para hacerlos llegar a una audiencia hambrienta de noticias sobre Trump y, cuando ese público comenzó a hacer clic en las historias y a compartirlas, empecé a ganar dinero de los ingresos publicitarios en la web. (Amorós, M., 2018, p. 37)

A nivel estatal, en 2017, el Consejo de Ministros aprueba la "Nueva estrategia de Seguridad Nacional" contra las "campañas de desinformación" y en 2019 se ha dado un paso más. El Gobierno ultima una unidad especializada contra las noticias falsas y el ciberterrorismo de cara a las próximas elecciones generales y europeas. Se trataría de la creación de una "unidad de control" que haga frente a la desinformación. Así lo explicó el ministro de Asuntos Exteriores, Unión europea y Cooperación, Josep Borrell. El titular de Exteriores constata la "gran preocupación" del Ejecutivo sobre las "noticias falsas, la desinformación y la propagación en la red de infundios que acaban por calar en la opinión de la gente".

Al tratarse de un tema de mucha actualidad e importancia tanto las instituciones, como los organismos periodísticos y los estudiosos no han tardado en reaccionar. Por ello podemos hacer un estado de la cuestión sobre las noticias falseadas. Sin embargo, no hay mucho sobre el caso concreto de estas noticias falseadas en el medio televisivo. Es lo que imprime interés y novedad a esta investigación.

\section{REVISIÓN TEÓRICA Y PLANTEAMIENTO DEL PROBLEMA}

Dentro de la revisión teórica del estudio abordado, primero intentaremos definir qué consideran los distintos autores noticia falseada, ya que no hay una definición homogénea, tanto es así que, en uno de los portales creados para combatirlas, Maldita.com, ahora se trabaja para no utilizar este término y pasar a usa el de "desinformación"

Porque 'f ${ }^{* * *} \mathrm{n}^{* * *}$ ' o 'noticia falsa' a día de hoy no significa lo mismo para todo el mundo: no existe un consenso sobre la definición. Si Maldita.es dice que tal o cual

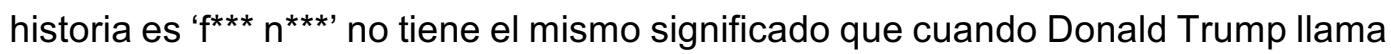
' $f^{* * *} n^{* * *}$ a CNN o al Washington Post. El término se ha convertido en un arma arrojadiza que políticos y colectivos utilizan para atacarse unos a otros queriendo hacer ver que tienen el patrimonio de la verdad. Este término, además, no explica la complejidad de la situación y genera confusión en los debates mediáticos y políticos. Tampoco define bien el fenómeno: si pensamos en 'noticias falsas' nos viene a la mente un formato determinado: un artículo, con su titular, su foto y su 
desarrollo y el problema es infinitamente más amplio: memes, capturas, vídeos, audios... esa es la desinformación a la que más expuestos estamos y cuando hablamos de ' $f^{* * *} n^{* * *}$ no la estamos teniendo presente. (2018)

A pesar de todo esto, nosotros en nuestro artículo vamos utilizar el término noticia falseada para referirnos al fenómeno que estamos viviendo.

Aclarado esto empecemos por la definición dada por First Draft, que es un proyecto del Harvard Kennedy School of Government. Ellos definen la desinformación como la mezcla del contenido falso y la intención de hacer el mal. Aunque quizás es más oportuno para nuestra investigación este otro término "la fabricación o manipulación deliberada de contenido audiovisual incluyendo la creación intencionada de rumores y teorías de la conspiración.

Incluir la definición dada por la Federación Internacional de Periodistas (FIP) que representa a 600 mil comunicadores en todo el mundo.

Este término es utilizado para conceptualizar la divulgación de noticias falsas que provocan un peligroso círculo de desinformación. Las redes sociales permiten que los usuarios sean productores y consumidores de contenidos a la vez, y han facilitado la difusión de contenido engañoso, falso o fabricado. Así se genera un circuito vicioso, y una noticia falsa se replica miles de veces en cuestión de segundos. (2018, p.2)

Señalar también la definición dada entre personas del mundo de los medios de comunicación. Así José Antonio Zarzalejos, periodista y exdirector de ABC y El Correo introduce elementos nuevos como la relativización de la veracidad:

La posverdad no es sinónimo de mentira, sino que "describe una situación en la cual, a la hora de crear y modelar la opinión pública, los hechos objetivos tienen menos influencia que las apelaciones a las emociones y a las creencias personales". La posverdad consiste en la relativización de la veracidad, en la banalización de la objetividad de los datos y en la supremacía del discurso emotivo. (2017, p. 11)

En la misma onda, pero yendo más allá, la definición hecha por el periodista José Antonio LLorente:

La divulgación de noticias falsas desemboca en una banalización de la mentira y, por ende, en la relativización de la verdad. El valor o la credibilidad de los medios de comunicación queda mermado frente a las opiniones personales. Los hechos pasan a un segundo plano, mientras el "cómo" se cuenta la historia retoma importancia y le gana al "qué". No se trata entonces de saber lo que ha ocurrido, 
se trata de escuchar, ver, leer, la versión de los hechos que concuerde más con las ideologías de cada uno. (2017, p. 9)

El hecho de que la credibilidad de los medios de comunicación quede mermada es el punto que hace tan importante el análisis de este fenómeno para los periodistas que actualmente trabajan en los medios de comunicación, en este caso en televisión.

Una vez indicado qué vamos a considerar noticia falseada, vamos a hacer un repaso sobre las reacciones o iniciativas que los distintos organismos han tenido respecto a su proliferación. Empezaremos por la Comisión Europea que dentro de su Código de Buenas Prácticas ha incluido estas noticias falsas, creando un grupo de 39 expertos de Alto Nivel para dar indicaciones sobre cómo actuar ante este problema.

También la Federación Internacional de Periodistas ha reaccionado creando la "Guía para combatir la desinformación en la época de la posverdad" en la que se incluye una definición de noticia falseada, un apartado donde se explica por qué se difunden, una contextualización de la época de la posverdad, una tipología de noticias falseadas, las $8 \mathrm{P}$ de la desinformación (1) Periodismo deficiente 2) Parodia 3) Provocación 4) Pasión 5) Partidismo 6) Provecho 7) Poder o influencia política 8) Propaganda), la relación entre fake news y Democracia, el rol que se debe adquirir ante las fake news, cómo detectarlas y cómo desmentirlas.

También en el ámbito audiovisual se ha reaccionado para dar herramientas a periodistas y telespectadores contra estos bulos. La Federación de Organismos de Radio y Televisión Autonómicos (Forta) ha considerado que el fenómeno de las noticias falsas prolifera en Internet "generando confusión y desconcierto" por lo que ha desarrollado un decálogo de consejos para facilitar a los internautas la detección de fake news. Bajo el título "Si dudas, no compartas", los medios audiovisuales públicos autonómicos englobados en Forta han publicado esta guía consensuada donde ponen de relieve los diferentes aspectos a tener en cuenta para detectar las noticias falseadas.

1. El titular. Se dice que a veces la realidad supera a la ficción...pero en contadas ocasiones. En la era de las redes sociales, los titulares tienen más importancia que nunca, por eso los que se refieren a noticias falsas suelen ser demasiado llamativos e incluyen afirmaciones difíciles de creer.

2. El autor. Si la noticia carece de firma, es un aspecto que puede hacernos sospechar. Las fake news generalmente tienden a ser anónimas y nunca incluyen el nombre del autor.

3. La fuente y el medio. Las noticias falsas suelen tener como fuente medios desconocidos, muchas veces que no habíamos oído nunca. 
4. La "exclusividad". Cuando la noticia es auténtica, es difícil que conserve la exclusividad y es muy probable que tenga repercusión en distintos medios. Si sólo aparece en uno de estos medios poco conocidos, mala señal.

5. El formato. Para llamar la atención, las fake news suelen contar con un formato peculiar, diferente al habitual, con colores y tamaños excesivamente llamativos, el uso desmedido de mayúsculas...

6. La fecha. Es otro punto a tener en cuenta. La actualidad prima y las noticias online reflejan pormenorizadamente la fecha e incluso la hora. Por el contrario, las informaciones falsas descuidan este aspecto, con fechas anticuadas 0 directamente obviando el dato.

7. La redacción. Una noticia de un medio creíble debe tener siempre una redacción impoluta. Cuando la información tiene errores en la puntuación, fallos ortográficos...desconfiemos.

8. Las imágenes y vídeos. El apoyo visual de las noticias es fundamental y las imágenes/fotografías/vídeos deben estar muy cuidados. Las noticias falsas se ilustran con imágenes sacadas de contexto o con retoques excesivos, con defectos. También pueden ser imágenes de baja calidad.

9. Los links. Las fake news tratan de simular las URLs de los medios habituales para ser más "creíbles" pero revisando los pequeños detalles de sus links, que además suelen dar error, se encuentran fallos y diferencias.

10. Los hechos. Las informaciones falsas hablan de hechos, datos...que difícilmente es posible verificar. Comprobarlos con una búsqueda de estos aspectos es muy útil para dar con un bulo.

También Facebook se unió antes del cierre de este artículo al hecho de intentar evitar las noticias en sus redes el 28 de abril, fecha de las últimas elecciones en España, no obstante, la plataforma mantenía que no era un cometido fácil.

Los propios responsables del despliegue de esa vigilancia asumen que hoy esta es una batalla muy difícil de ganar. Y la previsión de expertos en redes sociales y comunicación lo corrobora: las noticias falsas correrán como nunca por esos canales en busca del voto. Habrá dos campañas, una abierta, transparente y cívica. La otra será más oscura. (2019)

La muestra seleccionada está compuesta por los profesionales que actualmente cubren la información televisiva en Sevilla. Hemos acudido a profesionales que realizan su labor en los medios televisivos más representativos en Sevilla, uno por cada grupo de 
comunicación. Así hemos podido contar con el testimonio de profesionales que actualmente trabajan en el grupo Mediaset (Telecinco y Cuatro), en Atresmedia (Antena 3 TV y La Sexta), 13TV y Europapress. Para seleccionar a los componentes de esta muestra se ha exigido que los participantes ejercieran como periodistas en la actualidad, llevaran trabajando en los medios de comunicación un mínimo de 5 años y fueran licenciados en Comunicación.

En el método se ha recurrido tanto al análisis cuantitativo como cualitativo, y la aportación de las fuentes ha sido a través del cuestionario de respuestas abiertas. Asimismo, se ha utilizado la observación participante dado que la investigadora que lleva a cabo este trabajo ha ejercido durante más de una década en el medio televisivo.

No obstante, hemos encontrado limitaciones en el estudio. Teniendo en cuenta cómo es la labor de un periodista de televisión hemos pensado que era la mejor forma de poder acceder a todos ellos y que pudieran contestar a las preguntas cuando su labor diaria les permitiera era el uso del cuestionario abierto enviado a través de correo electrónico o, incluso, de aplicación móvil tipo WhatsApp. Así los entrevistados han ido respondido a su ritmo, enviando las respuestas a través de internet. Esto podía solucionar la mayor limitación que es que los periodistas, y más aun los que trabajan cubriendo la actualidad en televisión, tienen poco tiempo libre y por tanto para dedicarle a este cuestionario. Otra de las limitaciones es que los periodistas objeto de nuestro estudio siguen trabajando para el medio de comunicación al cuál se refieren al contestar dicho cuestionario, es decir hay una relación de dependencia laboral entre el periodista y el canal sobre el que habla en esta encuesta. Por tanto, como investigadores debemos presuponer que no podrán hablar en contra de dicho medio y quizás haya parcelas negativas que no incluyan en sus respuestas. Debemos estar atentos por si hay que añadir o corregir algún dato en este sentido. Asimismo, el hecho de hablar del desarrollo trabajo propio quizás también haga que los entrevistados no sean autocríticos por lo que tendremos que tener en cuenta esta cuestión ante los resultados obtenidos.

\section{RESULTADOS}

Ante la gran abundancia de canales de difusión de datos -que no siempre de información-, que actualmente existen los profesionales aseguran que para evitar ser víctima de noticias erróneas o falseadas hay que dar más importancia que nunca a las fuentes, ¿quién da ese dato? ¿Por qué?

La lucha por ser el primero, la carrera por darlo antes y la inmediatez que el desarrollo de las Nuevas Tecnologías de la Información, han provocado que aumente aún más si cabe el valor de nunca haber dado un dato erróneo o una información falseada. Se convierte por tanto en un baremo para determinar la calidad de un medio de comunicación o de un informador. 
Los periodistas entrevistados para este estudio hacen una clara distinción entre tres conceptos. No consideran lo mismo dar un dato erróneo, tras haber realizado todos los pasos correspondientes, con diligencia profesional; trasmitir una información no cierta que se podría haber evitado realizando con corrección el trabajo periodístico; y difundir una información falseada.

Además, aseguran que no sucumbir a dar informaciones falseadas, que debiera ser algo presupuesto en el profesional de la información, ahora se ha convertido en un mérito reconocido, ya que tras las múltiples cadenas de televisión no siempre hay profesionales de la información con la formación necesaria que la responsabilidad del derecho a la información solicita en ellos.

Como bien recoge la Constitución, un periodista se debe a su labor de dar noticias veraces, por eso si un periodista está difundiendo una noticia que sabe que no es cierta está incumpliendo con su deber como informador. Ante esto el único castigo es el hecho de que el telespectador deje de creer en determinado medio de comunicación o profesional, una pena importante en un mundo dirigido por las audiencias y los followers o seguidores.

Según los entrevistados, ésta es la mayor de las penalizaciones, que el medio pierda el prestigio y con ello la audiencia. No obstante, también subrayan que hay medios y profesionales que se arriesgan a dar "primicias" o informaciones "en exclusiva", muchas veces no contrastadas, que finalmente terminan siendo noticias falseadas pero la audiencia que han conseguido por ser los primeros les compensa. Pero, ¿y qué pasa a largo plazo? Quizás el día después se disculpen por esa información falsa a causa de la premura en darla, pero ¿y la próxima vez? ¿El público será tan vehemente? Según los profesionales, los espectadores saben cuándo se les miente. La cuestión es que muchas veces no se refleja en bajada de la audiencia. Hay público que sabe que un medio no dice la verdad, pero no por eso deja de acudir a él, es decir que no siempre lleva aparejada una bajada de espectadores. Sólo cuando un medio es castigado se replantea su dinámica ante las noticias falseadas.

Según el 'I Estudio sobre el impacto de las fake news en España' realizado por la consultora Simple Lógica en colaboración con la Universidad Complutense de Madrid, el $86 \%$ de la población española tienen importantes dificultades para diferenciar entre una noticia falsa y una verdadera. Ante esa realidad, las fake news están provocando el resurgir de la credibilidad de los medios de comunicación y los canales de comunicación tradicionales. El $60 \%$ de los usuarios encuestados por The Holme Report señala que el temor a las noticias falseadas les está llevando a informarse más por medios profesionales.

Yo creo que el problema deriva de la inmediatez que requiere nuestro trabajo. Eso nos lleva a recurrir, en muchas ocasiones, a las redes sociales, especialmente a 
Twitter, que permite acceder a la información casi en tiempo real pero que está al alcance de cualquiera. De forma que cualquier persona, con acceso a internet, puede difundir datos contrastados o no, explica Marta Álvarez, periodista de Informativos Telecinco. (2018)

Los buenos profesionales deben tener herramientas para combatir las noticias falseadas. "La mayoría de las informaciones falsas se trasmiten por interesas creados por lobbies empresariales y políticos, por eso los profesionales debemos combatirlas, ya que de darlas no estaría utilizando," explica Blanca A. Valseca, redactora de Europapress Televisión.

Entre las medidas para combatir las noticias falseadas, los periodistas enumeran las siguientes: identificar cuáles son las fuentes fiables, corroborar con otras fuentes, nunca dar por cierto un dato sin contrastarlo, analizar qué intereses puede haber detrás de que se conozca determinada noticia, no permitir que la repetición de determinados esquemas de noticias haga bajar la guardia a la hora de contrastar los datos y de pasar los filtros necesarios... En este último caso mencionan casos como las informaciones sobre violencia de género, aunque las historias sean parecidas, hay que hacer todas las comprobaciones necesarias antes de dar por cierta una información y además en este tipo de casos hay que huir de la empatía que te puede hacer perder la objetividad, según mantienen los entrevistados. También es importante confirmar si la información viene acompañada de algún material complementario, ya sea en papel o audiovisual, y el origen y la veracidad de estos con los profesionales correspondientes. Actualmente hay falsificaciones de gran calidad.

Por eso para poder distinguir las noticias falseadas el punto de partida es qué medio o persona da ese dato. Una vez conocido y valorada su reputación periodística habrá que contrastar la información, ver el interés que puede tener en que esa información sea pública y, en su caso, por qué te escoge a ti para darla, si te llega específicamente. Para ello hay que acudir a fuentes cercanas al dato dado y a su vez a organismos oficiales que puedan verificar dicho dato.

Marta Álvarez, reportera de Informativos Telecinco, explica:

Creo que hay forma de evitar las fake news en caso de no poder recurrir a las fuentes. Por ejemplo, ver cuál es el origen de confianza (si es una página web de confianza); si la noticia está firmada; si se han hecho eco otros medios de la información, si puede haber intencionalidad por parte del medio que la difunde, etc. A veces la inmediatez, las prisas, el querer ser el primero, es lo que hace que se den este tipo de informaciones. (2018)

Una de las trabas más señaladas, para sucumbir ante estas noticias falseadas por los entrevistados, es la inmediatez, el poco tiempo para procesar una información y la tiranía 
de ser el primero. Frente a la inmediatez de los nuevos canales de información, nos encontramos con que los tempos de las fuentes oficiales y los gabinetes de comunicación suelen ser muy distintos. Ante esto hay que valorar cuántas fuentes deben corroborar un dato para darlo como válido. Los entrevistados coinciden en que no hay un número concreto ni cerrado. Todo dependerá del hecho que vayamos contar y de su supuesta importancia.

Nuria Sánchez, reportera de La Sexta, expone

Evidentemente, no es lo mismo dar sin contrastar la información de que un hombre ha matado a su mujer o que un determinado político ha malversado, que no haber acudido a las fuentes suficientes que te confirman la hora exacta de la salida de una hermandad y darlo mal, por muy importante que sea para sus hermanos ese dato. La corroboración de un hecho es directamente proporcional a la importancia y relevancia de éste. (2018)

No obstante, otro cariz al que nos enfrentamos a la hora de valorar la importancia que tienen las noticias falseadas en el sentido de dar una información aun sabiendo que no es cierta.

Por ejemplo, si en un medio de comunicación se da una noticia de repercusión y en primicia, el aumento de la audiencia de ese día compensará, aunque al día siguiente se desmienta el hecho. Por eso muchas veces, aunque se sepa que puede tratarse de una noticia falseada llega a los medios de comunicación. "Se pueden llegar a dar fake news, el problema es que hay que analizar si compensa la buena audiencia de un día con la pérdida de credibilidad del periodista que da la información o del medio de comunicación en general," explica Nuria Sánchez, reportera de La Sexta.

Aunque se diga posteriormente que ha sido un fallo, que no debía haberse dado y se desmienta, el efecto multiplicador de los nuevos canales de información hace que la difusión del dato, sobre todo si ha sido intencionado, como en el caso de las noticias falseadas, sea imparable. Es más, recientemente un equipo de investigadores del Instituto Tecnológico de Massachusetts ha podido confirmar científicamente que las noticias falsas se extienden mucho más rápido que las verdaderas o reales. "La falsedad se difunde significativamente más lejos, más rápido, más profunda y más ampliamente que la verdad en todas las categorías de la información, y los efectos fueron más pronunciados para noticias políticas falsas...," aclaran los autores del estudio.

Eso en relación a la credibilidad de un periodista o un medio, pero ¿y en razón a la repercusión que tiene en la sociedad, en los espectadores, o incluso en el protagonista de esta noticia falseada? Existe por tanto lo que hemos considerado llamar el efecto "di que algo siempre queda" o las informaciones intencionadas como "globos sonda". Según los entrevistados, en estos casos suele compensar porque es mínimo el porcentaje de estos hechos que llegan a ser denunciados y si se denuncian muy poco 
llegan a ser condenados y en el caso remoto de que sea condenada la publicación de una información falsa, la pena no suele ser superior al dañado por la información vertida o el beneficio sacado por ella es mayor al castigo impuesto. Y esto, aunque la acción no tenga por qué ser denunciada solo por el afectado sino también por organismos concretos como el Defensor de Espectador. No obstante, en la mayor parte de los casos estos datos falsos o erróneos no son combatidos porque no compensa dado a que conllevan procesos judiciales y pocas garantías de éxito. En este caso, sólo la imagen del periodista o medio que difundieron la información quedará dañada. La realidad es que las mentiras se vuelven virales con más rapidez y facilidad que los desmentidos posteriores.

Los participantes de este estudio aseguran que no es habitual que un periodista dé en su medio de forma no consciente una noticia falseada. Aseguran que tienen los mecanismos necesarios para no darlas, pero mencionan casos concretos en que se han colado en las agendas de los medios. Por ejemplo, los entrevistados coinciden en mencionar casos como el de una mujer que denunció que había sido víctima de violencia de género por parte de su marido, los medios de comunicación contaron su testimonio y después se descubrió que se había autolesionado. Así lo explica la reportera de Noticias Cuatro, Irene Azcutia:

No conté la desaparición de una chica que aparecía en internet porque no pudimos corroborara a tiempo para el informativo con su familia que la estuviera buscando y la policía no tenía constancia de la hipotética denuncia. Finalmente, la desaparición no era cierta, y en algunos periódicos digitales se llegó a publicar. (2018)

Es frecuente también los bulos que circulan por la Red e incluso por los mensajes de teléfono móvil, por ejemplo, por WhatsApp, en los que se denuncia informaciones falsas e incluso es muy frecuente falsos secuestros de menores. Casos que cuya falsedad ha sido denunciada por la policía indicando el mal que provocan esos bulos a la difusión de casos reales cuando sí es necesario.

La cuestión es analizar además por qué se ha difundido esa noticia, si es por una broma, por un error o porque hay un interés de alguien en que haya miedo porque había madre que aseguraba que había una vecina molesta porque los niños jugaban en la calle a la pelota y le molestaba el ruido y desde la noticia falseada del secuestro ningún niño salía a la plaza y ya no había ruido. Mientras que otra aseguraba que había abierto un parque de bolas en la zona y que desde el bulo de los secuestros los niños en lugar de estar en la calle, los padres los dejaban en el parque de bola con el cuidador y el negocio había mejorado. ¿Qué interés hay por tanto detrás de que se difunda determinada noticia falseada? 
Otro caso que también es mencionado por los entrevistados es el de los disturbios en torno al 1 de octubre en Cataluña y se publicaron fotos de manifestantes supuestamente agredidos, con clara intencionalidad política, como señala Irene Azcutia:

Se trataban de fotografías de otras cargas en manifestaciones que no eran de ese día. En ese caso en concreto creo que a veces, como en este caso, se dan con un claro ejemplo de manipulación y además buscando el morbo. (2018)

Aunque sea de ámbito internacional también una de las entrevistadas ha mencionado el caso de las "mentiras" de Trump, indicando que muchas veces las noticias falseadas que el presidente americano da llegan más lejos que las verdaderas. Así Nuria Sánchez, reportera de La Sexta:

Pues al nivel local ocurre lo mismo, son más noticiosas, se habla más de ellas, por mucho que después se desmientan el que quería su difusión ha conseguido su objetivo, nuestro papel como periodistas es evitar ese uso interesado que se hace de nuestra profesión. Si sabemos que es falso no darlo y nuestros medios nos debería apoyar, lo que pasa es que a veces las noticias son tan suculentas y van a llenar tantos minutos y van a dar tanta audiencia que aun sabiendo que no pueden ser verdaderas se terminan dando, incluso añadiendo que es mentira o que es un posible bulo, pero se le da su tiempo, así solo se consigue que se vuelvan a dar y que vayan calando en el espectador. (2018)

En el momento de la realización de esta investigación estaba teniendo lugar las candidaturas a la Presidencia de Brasil y las noticas falseadas llenaron gran tiempo de la campaña política.

‘Esto es fake news!'. Es la expresión favorita de los votantes de Jair Bolsonaro cada vez que en la prensa aparece una noticia negativa sobre su candidato a la presidencia. No importa si hay vídeos que atestiguan la veracidad de la información, como los que muestran a Bolsonaro denigrando a gays, negros y mujeres. El candidato ultraderechista sostiene puntualmente que son falacias 0 que fueron sacados de contexto, mientras que los votantes se muestran dispuestos a creer a su versión, deseosos de que se produzca el tan ansiado cambio político en Brasil.(2018)

Aseguran que nunca antes las noticias falseadas habían tenido tanto protagonismo en una campaña electoral en el país. El equipo de Bolsano ha sido acusado formalmente de emplear noticias falsas contra el candidato de la oposición, y ya está siendo investigado por la Policía Federal. Las principales informaciones engañosas han sido difundidas por mensajería telefónica, es decir, por grupos de whatsapp, algo que hace que se difundan muy rápidamente. 
Por último, queremos introducir un caso de noticia falseada dentro de los medios de comunicación. Se trata de la información que saltó a las redes sociales tras las últimas elecciones andaluzas. Se publicó que la televisión autonómica Canal Sur estaba emitiendo una receta de cocina mientras tomaba posesión de su cargo el nuevo presidente de la Junta de Andalucía. Diversos medios se hicieron ecos e, incluso, algunos periodistas. En concreto, el Diario de Sevilla tituló 'El huevo de Canal Sural margen del Parlamento y explicaba que:

Treinta años después de comenzar sus emisiones, en el momento de proclamarse un presidente andaluz del PP, Canal Sur estaba emitiendo en ese instante... una receta de huevo de avestruz con jamón, de un restaurante de Dos Hermanas. "Son muy gordos mis huevos, Modesto", proclamaba el ventero a Modesto Barragán, director y conductor de Andalucía Directo (espacio de una productora de ex directivos de la era dura de control de la RTVA) mientras se sobreimpresionaba la noticia de la elección de Juan Manuel Moreno Bonilla. (2019)

No fue el único medio de comunicación que se hizo eco, también el periodista Antonio Burgos reproducía esta noticia falseada en su columna en el periódico $A B C$. Bajo el título 'El autobús de Canal Sur' indicaba

Cuando, si nada hubiera cambiado, hubieran seguido dando la programación mañanera, con una ventanita muda en un ángulo donde se hubiese visto, muy pequeñito y sin voz, el solemne acto del Salón de los Pasos Ganados (que no Perdidos) del Parlamento Andaluz. Si el día del debate de investidura no pusieron ustedes Canal Sur, porque son, como servidor, de los que no gastan RTVA, se perdieron el espectáculo lamentabilísimo que ha resumido Francisco Andrés Gallardo: "Treinta años después de comenzar sus emisiones, en el momento de proclamarse un presidente andaluz del PP, Canal Sur estaba emitiendo en ese instante... una receta de huevo de avestruz con jamón, de un restaurante de Dos Hermanas. "Son muy gordos mis huevos, Modesto", proclamaba el ventero a Modesto Barragán, director y conductor de "Andalucía Directo" (espacio de una productora de ex directivos de la era dura de control de la RTVA) mientras se sobreimpresionaba la noticia de la elección de Juan Manuel Moreno Bonilla." (2019)

Ni siquiera se molestó en contrastar la información. Escribió su artículo y después lo compartió en su twitter. Tuvo que ser un trabajador de "Andalucía Directo" a través de esta red social el que sacara a Antonio Burgos de su error. Mario Balbontín le corregía,

Con todo el respeto. Eso es FALSO. Mientras se emitía Andalucía Directo habían pasado horas de la investidura de Moreno. El "frame" que se usa en la esquina inferior derecha para ilustrar la noticia falsa, hace referencia al avance del informativo N2 q comenzaría minutos después. (2019) 
La cadena autonómica no tardó en desmentir esta noticia falseada. El propio subdirector general de la RTVA, Joaquín Durán, publicaba en sus redes sociales

Canal Sur desmiente que la televisión autonómica emitiese una receta de cocina en el momento del Debate de Investidura. Además, se interrumpió el programa de Juan Y Medio para ofrecer un avance especial en Canal Sur Televisión para dar en directo la votación de Investidura por parte del Parlamento andaluz de Juan Manuel Moreno como presidente de la Junta. Un especial que condujo el periodista Carlos María Ruiz. Canal Sur Televisión desmiente categóricamente que emitiera un reportaje sobre una receta gastronómica de huevos de avestruz en el programa 'Andalucía Directo' en el momento del Debate de Investidura. Se trata de un hecho falso, verificable por cualquier medio que quiera comprobarlo. A la hora de 'AD' ya había finalizado el debate. Cabe subrayar que Andalucía Directo comienza a las 18:00 horas y el debate finalizó una media hora antes. Precisamente se interrumpió el programa de Juan y Medio para ofrecer un avance especial en Canal Sur Televisión para dar en directo la votación de investidura por parte del Parlamento Andaluz de Juan Manuel Moreno como presidente de la Junta. Un especial que condujo Carlos María Ruiz. Además, la fórmula empleada por Canal Sur Televisión en esta ocasión con el debate de investidura del nuevo presidente de la Junta es la que se ha venido empleando en todas las legislaturas anteriores. Los debates se dieron en Canal Sur 2 antes de la creación de ATV y tras su creación en ATV, así como las tomas de posesión que siempre se han emitido en CSTV. No obstante, en esta ocasión, se ha realizado un mayor despliegue de cobertura del debate de investidura con más avances y de más duración en Canal Sur junto a la retransmisión íntegra por Canal Sur 2, 100\% accesible para la comunidad de discapacitados auditivos, por la web y las redes sociales de Canal Sur. (2019)

A partir de aquí salen los medios de comunicación a lanzar el desmentido. 'Canal Sur no emitía recetas durante la investidura de Juanma” corregía el Diario de Sevilla.

Una noticia falseada donde se unen distintos parámetros. Periodismo, política, poder, productoras "élites" de Canal Sur, Estructura de la Información... Por eso es tan importante que no sólo los ciudadanos se pregunten por qué se emite esa noticia, sino que los periodistas sean los primeros en cuestionarse qué interés hay detrás de la información que se va a hacer pública y en este caso en concreto si la información es o no interesada. En este caso es evidente que sí, ya que se trata de causar desprestigio en la televisión autonómica en un momento donde en el debate se encuentra si uno de los cambios al modificarse el signo del gobierno andaluz es el futuro de la televisión pública de Andalucía. 
Es tan amplio el número de ejemplos y van aumentando que incluso se han creado plataformas en las que van recogiendo las noticias falseadas que se hacen un hueco en los medios de comunicación. Así el portal Maldito Bulo que se autodefine como una herramienta periodística "para que no te la cuelen. Un proyecto de Maldita.es, que pertenece a La Sexta, para luchar contra la desinformación". En esta plataforma diariamente se incluyen noticias falseadas. Así, por ejemplo, en los últimos días se dio el titular "No, ni Sánchez ni su mujer, Begoña Gómez, han gastado 500.000 euros en mobiliario nuevo para La Moncloa", en el que se desmiente informaciones que había aparecido en medios como en Diario 6 o Caso Aislado, entre otros. Este portal se basa en datos suministrados directamente por Moncloa que reducen la inversión de 500.000 euros a 1.388 euros.

\section{DISCUSIÓN Y CONCLUSIONES}

El total de los entrevistados asegura que utiliza las Redes Sociales no solo como herramienta de trabajo sino como fuente de información. También el cien por cien de los profesionales que participan en esta investigación afirma que contrasta las informaciones que les llegan por estos canales recurriendo a fuentes oficiales como entidades gubernamentales, instituciones, organismos públicos, etc. Un $20 \%$ asegura que ha dado alguna información falsa y ha sido por no haber acudido a canales oficiales o por haber querido ser los primeros en dar la información y la inmediatez ha ido en detrimento de la calidad periodística... El total de los entrevistados confirma que tiene mecanismos para evitar las noticias falseadas, aunque no siempre los utilice. Todos coinciden en que lo óptimo es trabajar con buena diligencia profesional y acudir a fuentes oficiales antes de dar por veraz algo.

Una de las entrevistadas incluso señala un mecanismo nuevo para luchar contra estas noticias falseadas. De esta forma lo expone Irene Azcutia:

Existe una empresa, Newtral, que hace verificaciones de noticias presuntamente falsas a través de whatsapp. Mecanismos hay, pero no siempre se usan y cuando no se hace es sobre todo por la rapidez de querer ser los primeros en contarlo pese a todo y a todos. (2018)

La discusión surge ante la escasez de tiempo para contrastar, cuando los canales oficiales llevan un tempo distinto al de los periodistas. Ante esto, los entrevistados recurren a la deontología profesional y el derecho a la información. Coinciden en que mejor no publicar algo que no se ha contrastado que publicarlo a riesgo de que la información sea falsa con el consiguiente deterioro de la función social y del derecho recogido en la Constitución de recibir información veraz. De esta forma lo explica Blanca A. Valseca, redactora de Europapress Televisión:

Para luchar contra las fake news, que suelen tener detrás intereses creados por los lobbies empresariales y políticos, propondría para combatir las fake news que 
todas las informaciones estén firmadas por un periodista colegiado y para ellos que exista un colegio de periodistas y si aun así se da una noticia falsa se estudie cada caso y se penalice el hecho si es intencionado. (2018)

Tras la realización de esta investigación podemos concluir que los profesionales consideran que tienen herramientas para combatir las noticias falseadas, pero a su vez que la velocidad, la inmediatez, el valor de la primicia que actualmente los medios de comunicación imprimen en los profesionales, incluso la audiencia, hacen que en ocasiones estas falsas noticias interesadas lleguen a los medios y a los telespectadores.

Los descubrimientos de esta investigación abren puertas a futuros estudios. La investigadora que realiza este trabajo considera de interés académico analizar un caso concreto, un suceso específico, y ver que noticias falseadas tienen a los periodistas y cuáles les llegan a los ciudadanos a través de la televisión. Así se plantea una investigación futura sobre uno de los sucesos que más minutos en programas de Actualidad e informativos ha llenado en los últimos años en la televisión española. Se trata del caso de la desaparición y fallecimiento del pequeño Julen tras caer a un pozo en la localidad andaluza de Totalán (Málaga) el domingo 13 de enero de 2019. La cuestión es discernir sobre la función social del profesional de la información ante la sociedad a la hora de que estos no den a conocer noticias que son falseadas ni sabiéndolo ni no siendo consciente. La audiencia y la rapidez no pueden justificar que un profesional de la comunicación sea cómplice en la difusión de una noticia falseada.

Ante la necesidad de luchar contra estas noticias falsas interesadas los organismos que velan por los intereses de los espectadores ya se han puesto manos a la obra. Así además del decálogo creado por la Federación de Organismos de Radio y Televisión Autonómicos (Forta), la Federación de Asociaciones de Periodismo de Asociaciones de Periodismo (FAPE) han propuesto crear una asignatura de periodismo en los institutos para combatir las noticias falseadas. "Los adolescentes se informan por las redes sociales, un lugar donde la información verídica y las noticias falsas se presentan de una manera similar", comenta Nemesio Rodríguez, presidente de la FAPE.

El presidente de la entidad considera que las noticias falseadas son un problema vigente en la sociedad actual. Según un estudio publicado por Reuters Institute (organismo dependiente de la universidad de Oxford), los españoles son la segunda población más preocupada por las noticias falsas. Un $69 \%$ de los ciudadanos afirman estar preocupados por la incipiente avalancha de noticias falseadas a la que se ven expuestos. Por lo que cobra mayor importancia que los profesionales de la comunicación sepan distinguirlas y combatirlas y los elementos que se creen para que no lleguen a la sociedad.

Además de esta posibilidad de estudio futuro mencionada, hemos detectado otra más. Es cierto que en España están proliferando estudios e investigaciones sobre 
el poder político de estas noticias falseadas, sin embargo, remitiéndonos a la línea de estudio de uno de los gurús americanos de éstas, Jestin Coler, creemos necesario analizar los intereses económicos que hay detrás de estas noticias falseadas.

El objetivo de las noticias falsas con las que estoy, casi familiarizado, no de la propaganda patrocinada por el estado, el contenido hiper-partidista o las noticias con las que no está de acuerdo, es el dinero a través de la venta de anuncios. Las historias que funcionan mejor son aquellas que son de naturaleza sensacional, pero apelan al sesgo de confirmación del consumidor. Con el fin de maximizar las visitas de páginas y aumentar los ingresos, las historias tienen como objetivo crear una respuesta emocional para que los lectores compartan contenido. Esa respuesta emocional puede ser de esperanza, inspiración, enojo, miedo, etc., pero el objetivo final es compartir. Mientras que alcanzar a un solo lector es agradable, alcanzar a ese lector y sus cientos de contactos es mucho mejor. (2018)

Cabe terminar estos resultados incluyendo este texto rescatado de la mexicana Letras libres sobre el buen periodismo.

La aspiración de ser imparcial y la parcialidad transparente no agotan de ningún modo las opciones del buen periodismo. (...) En este caleidoscópico mundo de medios a la vez concentrados y fragmentados hay múltiples contratos diversos con el lector, telespectador o usuario. Lo esencial es que exista ese contrato, sobre el cual se construye la confianza. Esta se pierde cuando el contrato es violado por el escritor, bloguero, responsable de la emisión o quien publica en una red social. (2017, p.11)

La mejor forma de combatir las noticias falseadas es no romper este contrato. Y como bien señala el periodista Juan Tortosa (2018) en la presentación en Sevilla de su libro Periodistas, el arte de molestar al poder, "ante cualquier duda la respuesta es siempre el periodismo de calidad."

\section{Referencias}

ABC (2017). El burlo del intento de secuestro de una niña en Sevilla. Recuperado de https://bit.ly/2Wxpjzq

ABC (2019). El autobús de Canal Sur. Recuperado de https://bit.ly/31j79QV

Amorós, Marc. (2018). Fake news, La veradad de las noticias falsas. Barcelona: Plataforma editorial

Boletín Oficial del Estado (1978). Constitución Española. Recuperado de https://bit.ly/1KoXXzL 
Carrera, P. (2018). Estratagemas de la posverdad. Revista Latina de Comunicación Social, 73, pp. 1469 a 1482.

Castells, M. (2009). Comunicación y poder. Madrid: Alianza Editorial. Paidós.

Coler, J. (2018). About... Recuperado de https://bit.ly/2Kwwy3E

Diario de Sevilla (2019). El huevo de Canal Sur al margen del Parlamento. Recuperado de https://bit.ly/2XAlPss

El Confidencial (2018). Un 97\% de fake news en Whatsapp: ¿campaña coordinada para que gane Bolsonaro? Recuperado de https://bit.ly/2Kwnc82

El Mundo (2017). 'Fake news', palabra del año en el Diccionario Oxford. Recuperado de https://bit.ly/2EYYh9r

El País (2009). Once meses en la cárcel por falsas denuncias de maltrato. Recuperado de https://bit.ly/2lyNjXd

Europapress (2018). Medios audiovisuales públicos autonómicos lanzan el decálogo 'Si dudas, no compartas' Para ayudar a detectar 'fake news'. Recuperado de https://bit.ly/2MzG2Of

Federación Internacional de Periodistas (2018). ¿Qué son las fake news? Guía para combatir la desinformación en la Era de la Posverdad. Recuperado de https://bit.ly/2YJ553h

Fundeu (2017). Noticias falsas o falseadas mejor que fake news. Recuperado de https://bit.ly/2SDc7TW

Illades, E. (2018). Fake news. La Nueva Realidad. México: Grijalbo.

La Sexta (2017). No dice la verdad el 70\% de las veces... Trump, 'el mentiroso', esta noche en Equipo de Investigación. Recuperado de https://bit.ly/2FaPLEH

Lotero-Echeverri, G., Romero-Rodríguez, Pérez-Rodríguez, M. A. (2018). Fact-checking vs. Fake news: Periodismo de confirmación como recurso de la competencia mediática contra la desinformación. Index comunicación 8 (22), 295-316.

Maldita (2018). Dejemos de hablar de 'fake news' y de 'noticias falsas'. Recuperado de https://bit.ly/2AluuzR

Palomo, B., Sedano, J. (2018). WhatsApp como herramienta de verificación de fake news. El caso de B de Bulo. Revista Latina de Comunicación Social, 73, pp. 1384 a 1397.

Radiotelevisión Española (2019). El gobierno ultima una unidad contra las 'fake news' y el ciberterrorismo de cara a las elecciones. Recuperado de https://bit.ly/2XyZWtJ

Reig, R., Labio, A. (2017). Laberinto mundial de la Información. Estructura mediática y poder. Barcelona: Anthropos. 
Reig, R. (2003). Estructura y Mensaje en la Sociedad de la Información. Sevilla: Mergablum Edición y Comunicación.

Reig, R. (2011). Los dueños del Periodismo. Barcelona: Gedisa.

Revista Uno. (2017). La era de la posverdad: realidad vs. percepción.

Revista Muy Interesante. (2018). La ciencia confirma que las 'fake news' se extienden más rápidamente que la verdad. Recuperado de https://bit.ly/2rqaWvA

Suarez Villegas, J. C., Cruz Álvarez, Jesús (2016). Desafíos éticos en el periodismo digital. Madrid; Dykinson.

Tortosa, J. (2018). Periodistas, el arte de molestar al poder. Barcelona: Roca editorial.

Urías Martínez, J. (2003). Lecciones de derecho de la Información. Madrid: Tecnos. 